\title{
Quantification of lithium at ppm level in geological samples using nuclear reaction analysis
}

\author{
Nathaly De La Rosa ${ }^{1} \cdot$ Per Kristiansson ${ }^{1} \cdot$ E. J. Charlotta Nilsson ${ }^{1} \cdot$ Linus Ros $^{1} \cdot$ Jan Pallon $^{1} \cdot$ Henrik Skogby ${ }^{2}$
}

Received: 22 January 2018/Published online: 28 May 2018

(c) The Author(s) 2018

\begin{abstract}
Proton-induced reaction $(\mathrm{p}, \alpha)$ is one type of nuclear reaction analysis (NRA) suitable especially for light element quantification. In the case of lithium quantification presented in this work, accelerated protons with an energy about of $850 \mathrm{keV}$ were used to induce the ${ }^{7} \mathrm{Li}(\mathrm{p}, \alpha)^{4} \mathrm{He}$ reaction in standard reference and geological samples such as tourmaline and other $\mathrm{Li}$ minerals. It is shown that this technique for lithium quantification allowed for measurement of concentrations down below one ppm. The possibility to relate the lithium content with the boron content in a single analysis was also demonstrated using tourmaline samples, both in absolute concentration and in lateral distribution. In addition, Particle induced X-ray emission (PIXE) was utilized as a complementary IBA technique for simultaneous mapping of elements heavier than sodium.
\end{abstract}

Keywords Nuclear reaction analysis (NRA) - Lithium quantification · Particle induced X-ray emission (PIXE) · Geological samples · Double-sided silicon strip detector (DSSSD)

\section{Introduction}

Lithium, as an alkali metal, is a highly reactive element, and as a consequence of this, lithium does not appear as an isolated metal in nature. Instead, it combines with other elements to form minerals or other natural compounds [1]; for instance, lithium occurrence is common in some ferromagnesian minerals where it partly substitutes magnesium [2].

Lithium can be found in many natural brines, nearly all igneous rocks, as a low concentration constituent. Lithium is also found as a stoichiometric component in some minerals such as spodumene, lepidolite, petalite, and amblygonite [3]. J. Arfwedson discovered lithium as an elemental species in petalite at the beginning of the 19th century but industrial relevance came around forty years later [2]. Nowadays, lithium is of great interest to

Nathaly De La Rosa

Nathaly.DeLaRosa@nuclear.lu.se

1 Division of Nuclear Physics, Department of Physics, Lund University, Box 118, 22100 Lund, Sweden

2 Department of Geosciences, Swedish Museum of Natural History, Box 50007, 10405 Stockholm, Sweden investigate for instance, the primordial lithium problem in cosmology [4], treatment of bipolar disorder, Alzheimer's disease, and thyroid cancer [5], as shielding material in nuclear reactors [6], in Li-ion batteries [7] and in geological processes such as magmatic differentiation, seawaterbasalt interaction [8] and crust-mantle recycling [9].

In many of the aforementioned applications, techniques capable of measuring as low concentrations of lithium as a few ppm are required. Ion induced reactions, elastic recoil detection analysis (ERDA), and neutron induced methods are sensitive nuclear techniques that have been utilized to quantify lithium [10]. Proton induced reactions are one type of ion induced reactions most commonly chosen for analysis of lithium. Proton irradiation can yield prompt $\gamma$ ray emission, neutron emission, $\alpha$-particle emission, etc., depending mainly on the energy of the incident proton [11].

In the study reported in this paper, lithium analysis in geological samples was carried out at the Lund Ion Beam Analysis Facility (LIBAF) using the reaction ${ }^{7} \mathrm{Li}(\mathrm{p}, \alpha)^{4} \mathrm{He}$. This reaction has been selected for lithium quantification, since it has a high Q-value of about $17 \mathrm{MeV}$, a favorable cross-section [12] and produces two $\alpha$ particles that are easily distinguished from scattered beam particles and 
other reaction products [13]. The ${ }^{7} \mathrm{Li}(\mathrm{p}, \alpha)^{4} \mathrm{He}$ cross-section increases smoothly in the proton beam energy interval $0-2.5 \mathrm{MeV}$ with a maximum of $3.3 \mathrm{mb} / \mathrm{sr}$ at $2.5 \mathrm{MeV}$. In the present work, the lithium reaction was induced by protons with energies of $852 \mathrm{keV}$. At this energy, the crosssection is $0.5 \mathrm{mb} / \mathrm{sr}$ at $150^{\circ}$ [12]. Particle Induced X-ray Emission (PIXE) was performed simultaneously with Nuclear Reaction Analysis (NRA) and hence enabled the possibility to study spatial correlations between concentrations of heavier matrix elements and the lithium.

In previous work [14], the reaction ${ }^{7} \mathrm{Li}(\mathrm{p}, \alpha)^{4} \mathrm{He}$ yield and detection limits were studied as a function of the energy of the incident proton beam. In that work, we confirmed that the NRA technique can be routinely used for measuring lithium in geological materials, with concentrations down to a few ppm.

In order to further illustrate the capability of the technique and contribute to a number of geological investigations (e.g. [15],) selected geological samples belonging to the tourmaline group were analyzed. Tourmaline is a borosilicate mineral that presents a constant concentration of boron (approx. 3\%) with a quite variant composition [16]. Its generic formula is

$$
\mathrm{XY}_{3} \mathrm{Z}_{6}\left(\mathrm{~T}_{6} \mathrm{O}_{18}\right)\left(\mathrm{BO}_{3}\right)_{3} \mathrm{~V}_{3} \mathrm{~W} \text {, }
$$

where the $\mathrm{X}, \mathrm{Y}, \mathrm{Z}, \mathrm{T}, \mathrm{V}$ and $\mathrm{W}$ sites can be occupied as following, $\mathrm{X}=\mathrm{Na}, \mathrm{Ca}, \mathrm{K}$, or vacancies; $\mathrm{Y}=\mathrm{Mg}, \mathrm{Fe}, \mathrm{Mn}$, $\mathrm{Li}, \mathrm{Cr}, \mathrm{Al} ; \mathrm{Z}=\mathrm{Al}, \mathrm{Mg}, \mathrm{Ti}, \mathrm{V}, \mathrm{Cr}, \mathrm{Fe} ; \mathrm{T}=\mathrm{Si}, \mathrm{Al} ; \mathrm{V}=\mathrm{OH}$, $\mathrm{O} ; \mathrm{W}=\mathrm{OH}, \mathrm{F}, \mathrm{O}$. Tourmalines are organized according to the type of element that occupies the X, Y, Z, T, V and W sites [17]. For the alkali-group tourmalines, elbaite is the lithium-bearing type, $\mathrm{Na}\left(\mathrm{Li}, \quad \mathrm{Al}_{3}\right)_{3} \mathrm{Al}_{6}\left(\mathrm{Si}_{6} \mathrm{O}_{18}\right)\left(\mathrm{BO}_{3}\right)_{3}(-$ $\mathrm{OH}, \mathrm{F})_{4}$, dravite is the magnesian, $\mathrm{NaMg}_{3} \mathrm{Al}_{6}\left(\mathrm{Si}_{6} \mathrm{O}_{18}\right)(-$ $\left.\mathrm{BO}_{3}\right)_{3}(\mathrm{OH}, \mathrm{F})_{4}$, and schorl the ferrous type $\mathrm{Na}(\mathrm{Fe}, \mathrm{Mn})_{3}$ $\mathrm{Al}_{6}\left(\mathrm{Si}_{6} \mathrm{O}_{18}\right)\left(\mathrm{BO}_{3}\right)_{3}(\mathrm{OH}, \mathrm{F})_{4}[18]$.

Tourmaline group minerals are complex borosilicates and their crystal structure and crystal chemistry have been widely studied. They are known as valuable indicator minerals that can provide information on the compositional evolution of their host rocks, chiefly due to their ability to incorporate a large number of elements. They frequently show intricate crystal-growth patterns related to changes in the crystallization environment [19].

\section{Experimental}

Probing protons, capable of triggering the nuclear reaction ${ }^{7} \mathrm{Li}(\mathrm{p}, \alpha)^{4} \mathrm{He}$, were generated with the single-ended $3 \mathrm{MV}$ Pelletron accelerator located at LIBAF. Detailed descriptions of the LIBAF are published in Refs. [20, 21]. The samples were irradiated with a focused $3 \mathrm{nA}$ proton beam with a $50 \mu \mathrm{m}$ diameter. The proton beam energy was selected, based on the previous work [14], to be $852 \mathrm{keV}$, since at this energy the peaks from the reactions ${ }^{7} \mathrm{Li}(\mathrm{p}, \alpha){ }^{4} \mathrm{He},{ }^{19} \mathrm{~F}(\mathrm{p}, \alpha){ }^{16} \mathrm{O}$, and ${ }^{11} \mathrm{~B}(\mathrm{p}, \alpha) 2 \alpha$ will be wellseparated in the energy spectrum. The choice of beam energy took also into account factors such as lithium cross section and interferences from other reactions.

In Fig. 1, the experimental arrangement is schematically illustrated. The $\alpha$-particles produced in the reaction and emitted in backward direction, were detected using a double-sided silicon strip detector (DSSSD) with 2048 pixels. This detector is a hollow disk with a thickness of $310 \mu \mathrm{m}$. Its outer and inner active diameters are $85 \mathrm{~mm}$ and $14 \mathrm{~mm}$ respectively, which provides an active solid angle of $2 \mathrm{sr}$, assuming a sample located $26 \mathrm{~mm}$ from the detector. In total, there are 96 strips, 64 stripes on front and 32 concentric rings on the back, each operated as a single surface barrier detector with e.g. similar shaping time and count rate behavior. A thorough explanation and technical specifications of the DSSSD can be found in Ref. [22].

The fact that the DSSSD is pixelated enables the use of high beam currents for NRA experiments, as the pixilation gives excellent pile-up suppression capability by the possibility to set multiplicity conditions on an event-by-event basis. With a traditional annular detector covering approximately the same solid angle a beam current around $200 \mathrm{pA}$ was the typical possible to use. With the DSSSD, dividing the particle flux between many pixels a typical current convenient to use is instead $5 \mathrm{nA}$. With this current it is still possible to focus the beam to get a spatial resolution better than $10 \mu \mathrm{m}$. In the present system the limiting factor is the data rate that can be transferred and stored, but for the type of reactions studied here this can be solved by increasing the threshold.

Simultaneously with the NRA, PIXE analysis was carried out, as this technique enables the study of the presence of heavier elements in the samples, thus, it is possible to study correlations between heavier elements and Li. A $50 \mathrm{~mm}^{2}$ silicon drift detector was employed to identify the characteristic X-rays [23].

Samples of well-known chemical composition, as minerals with stoichiometric $\mathrm{Li}$ contents and standard reference materials, and a set of tourmaline crystals were utilized in the experiment. Lithiophosphate, amblygonite, spodumene, petalite and eucryptite were the Li-minerals employed, whose lithium concentration ranges from 2 to 18\%. Two Standard Reference Materials (SRM) produced by the National Institute of Standards and Technology (NIST) were also used. The standard reference samples are SRM 610 and SRM 612 and they have a lithium concentration of 493(20) ppm and 44(3) ppm respectively $[24,25]$. In addition, eight tourmaline samples were analyzed in order to study the relation between boron and lithium concentration and a $\mathrm{Li}$-free synthetic quartz 


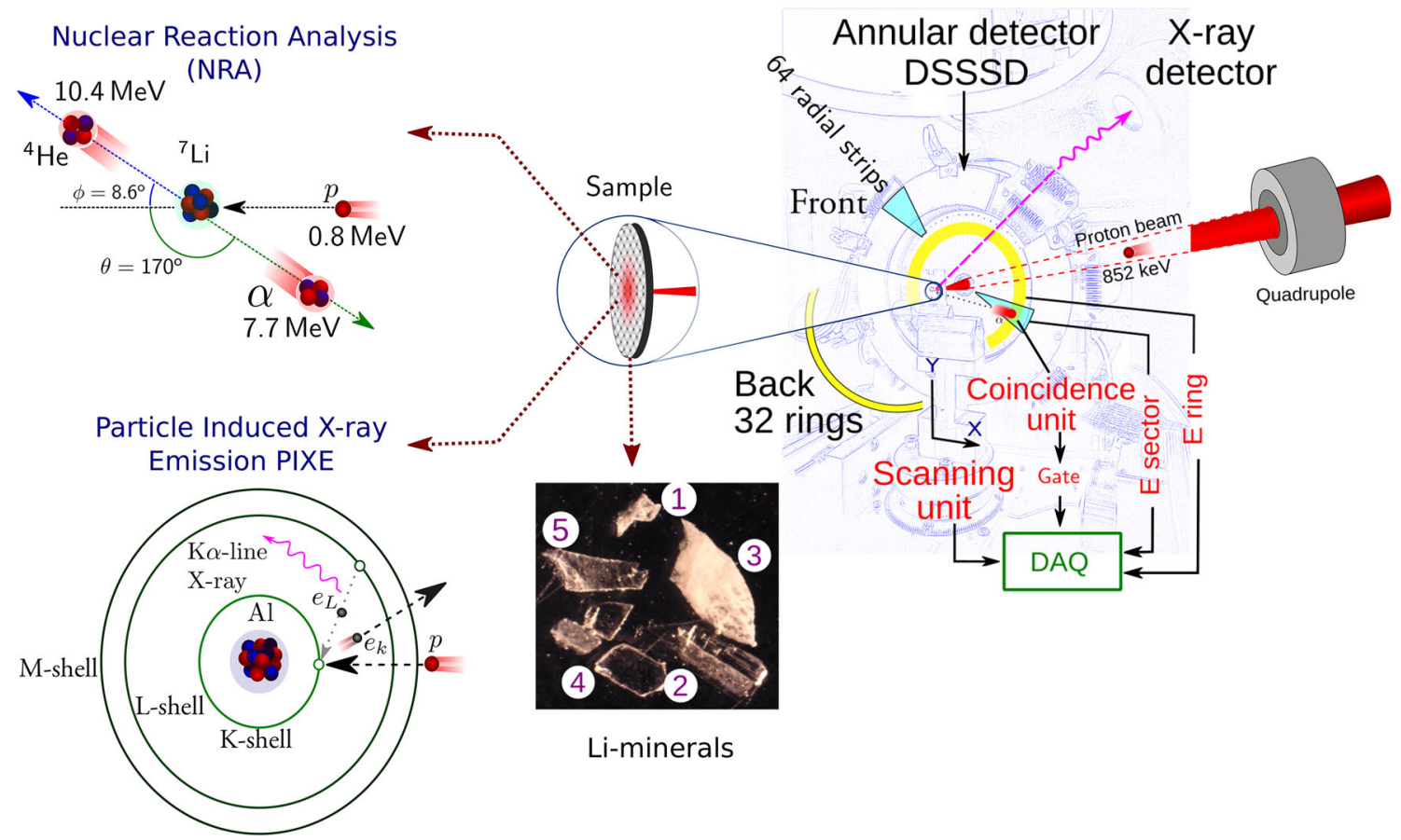

Fig. 1 Schematic illustration of the experimental set-up. Energetic protons can induce $\alpha$-particle and X-ray emissions in materials. In NRA, a proton at $0.8 \mathrm{MeV}$ reacts with a target ${ }^{7} \mathrm{Li}$ nucleus producing two $\alpha$-particles. One is ejected in the backward direction relative to the beam and the second in the forward direction. The reaction parameters shown are calculated based on kinematic equations. Only $\alpha$-particles ejected in the backward direction were detected with an annular detector. When an $\alpha$-particle hits the DSSSD two energy signals are generated, one from a sector (front side) and other from a ring (back side). The simultaneous detection of those signals produces a gate that is processed by the DAQ system. In PIXE, inner shell ionizations caused by the proton beam are followed by electron deexcitations to fill inner shell vacancies and characteristic X-ray emission. The samples were scanned with a proton beam at $852 \mathrm{keV}$. The photo shows one of the samples used; it has five Li-minerals whose names are listed in Table 1

Table 1 Lithium yield $\mathrm{Y}_{\mathrm{Li}}$ and lithium concentrations $\delta_{\mathrm{Li}}$ in Li-minerals and reference standard samples

\begin{tabular}{|c|c|c|c|c|c|}
\hline \multirow[t]{2}{*}{ Li-minerals } & \multirow[t]{2}{*}{$\mathrm{Y}_{\mathrm{Li}}$} & \multicolumn{4}{|c|}{ Li concentration $\delta_{\mathrm{Li}}(\%)$} \\
\hline & & $\delta_{\mathrm{Li}}=11.18(10) \mathrm{Y}_{\mathrm{Li}}$ & $\begin{array}{l}\text { Ranges }(\mu \mathrm{m}) \\
\mathrm{R}_{\mathrm{i}}\end{array}$ & $\begin{array}{l}\text { With } \mathrm{R}_{\mathrm{SP}} \text { corrections } \\
\delta_{\mathrm{Li}}=11.46(12) \mathrm{Y}_{\mathrm{Li}}\end{array}$ & $\begin{array}{l}\text { Nominal values } \\
\delta_{\mathrm{Li}}\end{array}$ \\
\hline 1. Lithiophosphate $\mathrm{Li}_{3} \mathrm{PO}_{4}$ & $1.54(5)$ & $18.0(6)$ & 27.4 & $17.7(6)$ & 18.0 \\
\hline 2. Eucryptite $\mathrm{LiAlSiO}_{4}$ & $0.50(1)$ & $5.7(2)$ & 28.6 & $5.7(2)$ & 5.5 \\
\hline 3. Amblygonite $\mathrm{LiAl}\left(\mathrm{PO}_{4}\right) \mathrm{F}$ & $0.42(1)$ & $4.7(2)$ & 27.9 & $4.8(2)$ & 4.7 \\
\hline 4. Spodumene $\mathrm{LiAlSi}_{2} \mathrm{O}_{6}$ & $0.32(1)$ & $3.7(1)$ & 27.7 & $3.7(1)$ & 3.7 \\
\hline 5. Petalite $\mathrm{LiAl}\left(\mathrm{Si}_{4} \mathrm{O}_{10}\right)$ & $0.20(1)$ & $2.3(1)$ & 27.9 & $2.3(1)$ & 2.3 \\
\hline NIST 610 & $4.4(2) \times 10^{-3}$ & 497(20) ppm & - & 501(20) ppm & $488_{-60}^{+33} \mathrm{ppm}$ \\
\hline NIST 612 & $4.0(3) \times 10^{-4}$ & 45(3) $\mathrm{ppm}$ & - & 46(3) $\mathrm{ppm}$ & $40_{-5}^{+3} \mathrm{ppm}$ \\
\hline
\end{tabular}

$\delta_{\mathrm{Li}}$ was obtained using the calibration shown in the Fig. 5. The $\delta_{\mathrm{Li}}$ uncertainties are calculated using error propagation of the formulas obtained in the calibration. $\mathrm{R}_{\mathrm{SP}}$ corrections were calculated based on the $\mathrm{R}_{\mathrm{i}}$ ranges listed below. Nominal values of $\delta_{\mathrm{Li}}$ for Li-minerals are concentrations calculated based on ideal stoichiometric formulas. In the case for NIST 610-612, nominal values of $\delta_{\mathrm{Li}}$ were taken from the Ref [24, 25]

(Suprasil quartz crystal) [26] was analyzed to estimate the background, i.e. the signal under the Li-peak.

According to the reaction under study, lithium presence in samples is associated with detection of $\alpha$-particles emitted in the reaction. Therefore, Li-mineral samples with a known composition were used to investigate the relation between lithium concentration $\delta_{\mathrm{Li}}$ and the number of detected $\alpha$-particles. Lithium concentration $\delta_{\mathrm{Li}}$ is the lithium percentage calculated based on stoichiometric formulas, and the number of $\alpha$-particles is the integrated peak counts $\left(C_{\mathrm{Li}}\right)$ in the energy range of $7-8.1 \mathrm{MeV}$ in an energy spectrum. 
In order to compare the $\mathrm{C}_{\mathrm{Li}}$ values from various samples, $\mathrm{C}_{\mathrm{Li}}$ values are extracted from $\alpha$-particle spectra, that should be normalized to the total charge used for the irradiation and compensated for the live time of the DAQ system, resulting in the $\mathrm{Li}$ yield from the sample, $\mathrm{Y}_{\mathrm{Li}}$ $=\mathrm{C}_{\mathrm{Li}} / \mathrm{Q}$. Details about this normalization process are given in Ref. [27]. Q is the total number of impinging proton on the sample, which is measured with a precision of 3\% using a pre-chamber Faraday cup and a fast-blanking electrostatic beam deflector [28]. To achieve $\mathrm{C}_{\mathrm{Li}}$ values comparable between different samples, there is also a need to normalize $\mathrm{C}_{\mathrm{Li}}$ to the volume analyzed since the range of the beam particles depends of the matrix composition. The reason is that the energy loss per length unit depends mainly on the electron concentration and this is related to the ratio between protons and neutrons in the matrix nuclei. For samples with a major element composition with the $\mathrm{p} / \mathrm{n}$ ratio around one, the variations of the correction between different matrixes are in the order of a few percent, but e.g. samples in the rare earth element (REE) region requires much larger volume corrections.

The ranges $R_{i}$ of different samples were calculated using the Stopping and Range of Ions in Matter software (SRIM) [29]. Thus, the factor $R_{S P}$ for each sample is the ratio of its range $R_{i}$ and the range in the reference sample, $R_{H}$. This correction was applied only to samples with a well-known chemical composition such as the Li-minerals. For unknown or partly known samples an additional error should be added.

Plotting $\mathrm{Y}_{\mathrm{Li}}$ as a function $\delta_{\mathrm{Li}}$ render an expression of $\delta_{\mathrm{Li}}$ for any $\mathrm{Y}_{\mathrm{Li}}$, hence it was possible to quantify the $\mathrm{Li}$ content in samples that have an unknown concentration of lithium, here illustrated by a set of tourmalines. These samples have

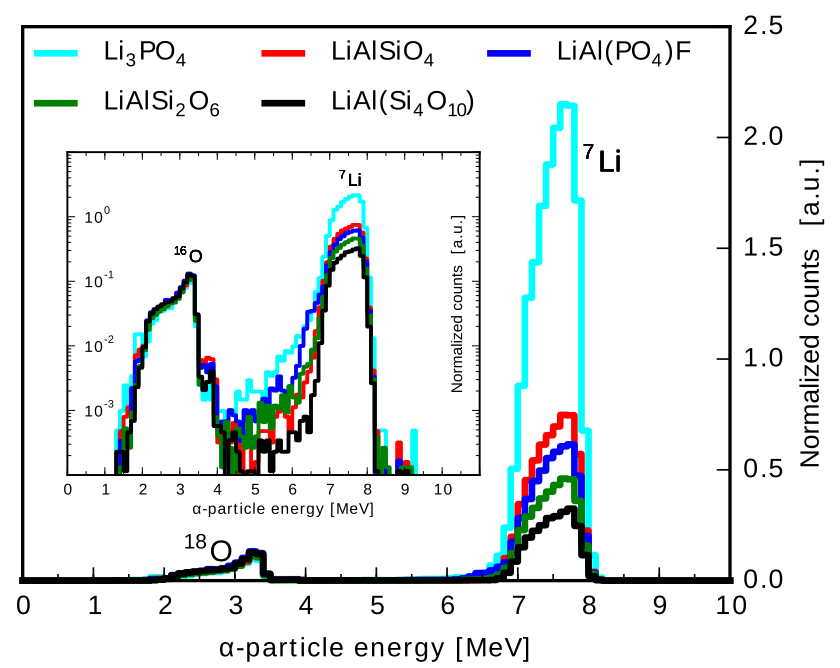

Fig. 2 Normalized energy spectra of the $\alpha$-particles produced in the reaction of protons at $852 \mathrm{keV}$ with lithium atoms within the Limineral samples. The inset is a semi-log version of the spectra
Raw (counts)

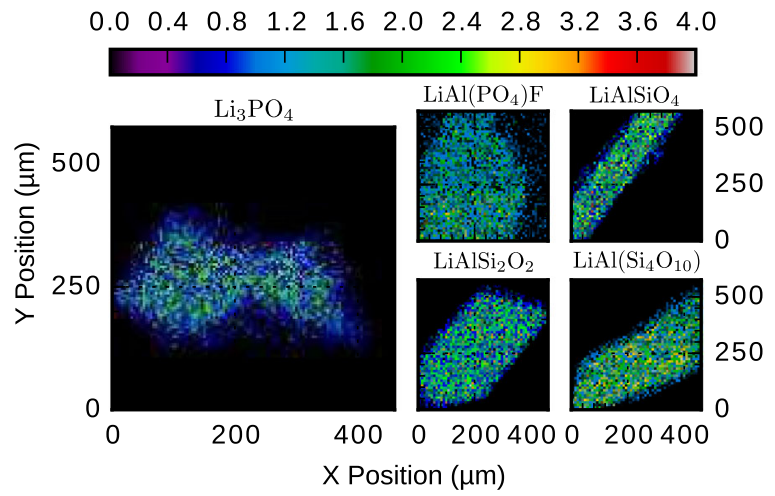

Fig. $32 \mathrm{D}$ maps of the Li-minerals obtained with backscattered protons

a high boron content, which was possible to measure simultaneously, since the reaction ${ }^{11} \mathrm{~B}(\mathrm{p}, \alpha) 2 \alpha$ can occur under the same conditions as used for lithium analysis. The energy distribution of the $\alpha$-particles produced in proton- ${ }^{11} \mathrm{~B}$ reactions is extended to $6 \mathrm{MeV}$. According to Ref. [27], boron analysis can best be performed using a narrow energy interval 3.3-4.3 MeV. In order to assess the relation between boron concentration $\delta_{\mathrm{B}}$ and boron yield $\mathrm{Y}_{\mathrm{B}}$, the NIST samples and a tourmaline crystal were analyzed according to the method described in Ref. [27]. Thus, it was possible to study lithium content as a function of boron content in tourmaline samples.

\section{Results and discussion}

The $\alpha$-particle energy spectra presented in Fig. 2 were acquired during the irradiation of Li-mineral samples with protons with the energy $852 \mathrm{keV}$. Each spectrum exhibits $\alpha$-particle distributions around $3 \mathrm{MeV}$ and $7 \mathrm{MeV}$. The peak around $3 \mathrm{MeV}$ consists of $\alpha$-particles originating from the reaction ${ }^{18} \mathrm{O}(\mathrm{p}, \alpha){ }^{15} \mathrm{~N}$, so these distributions are labeled $\mathrm{O}$. The distributions between $7 \mathrm{MeV}$ and $8 \mathrm{MeV}$ are

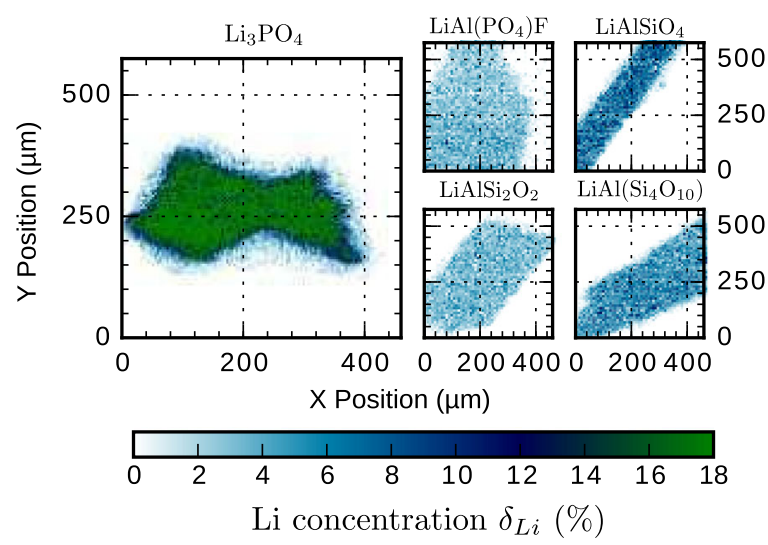

Fig. 4 2D Li distribution maps of the Li-minerals 


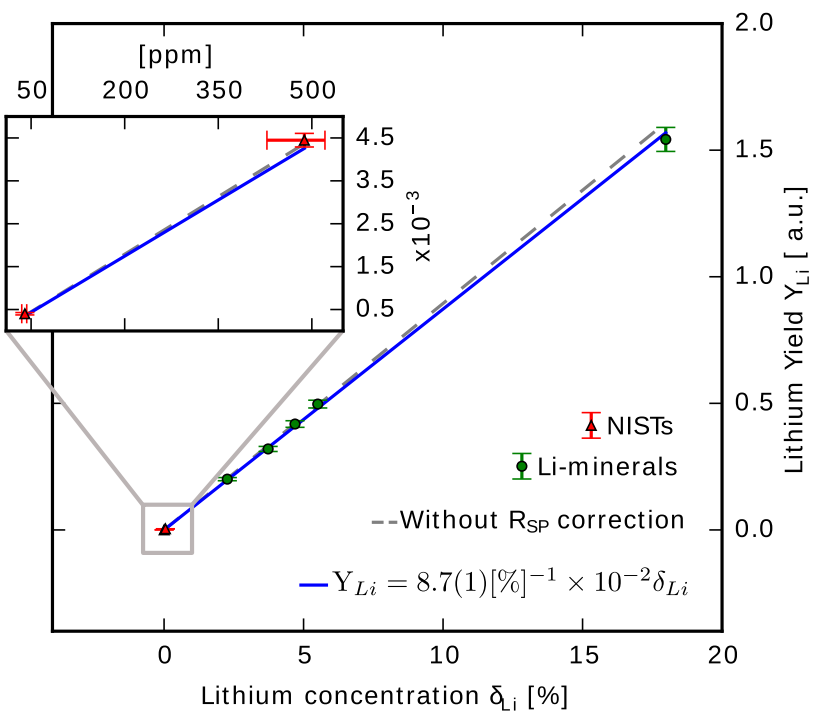

Fig. 5 Lithium yield $Y_{\mathrm{Li}}$ as a function of lithium content in the crystals listed in Table 1 . Based on $\mathrm{Y}_{\mathrm{Li}}=\mathrm{R}_{\mathrm{SP}} \mathrm{C}_{\mathrm{Li}} / \mathrm{Q}$, the $\mathrm{Y}_{\mathrm{Li}}$ error bars were derived from error propagation calculations, taking into account that the $R_{S P}$ range factor uncertainty is negligible, the $C_{L i}$ uncertainty is calculated as $\sqrt{\mathrm{C}_{\mathrm{Li}}}$, and $\mathrm{Q}$ uncertainty is $3 \%$

related to $\mathrm{Li}$ from the studied reaction, so this distribution is labeled Li. As can be seen in Fig. 2, the intensity of the Li-peak is proportional to the lithium concentration in the samples.

The analysis of a sample is performed in two steps. First, the elastically backscattered protons are measured in order to obtain a fast image of the sample, see Fig. 3. This 2D-preview helps us to select a desired scan area within a crystal. Thus, unnecessary scanning of areas outside the crystal is minimized, and so the time spent on analysis is optimized. The number of backscattered protons used for image reconstruction is called Raw counts. The Li measurement takes place in the second step of the analysis. A scanning area of interest is selected, within the boundaries of the image taken in the first step, and scanned with the proton beam, which causes protons and lithium to react. The $\alpha$-particles emanating from lithium in the defined area are measured and used to create a 2D distribution map, see Fig. 4.

In Fig. 5, the correlation between measurements of different samples with different lithium concentrations $\delta_{\mathrm{Li}}$ is shown; the $\delta_{\mathrm{Li}}$ values are reported in wt-ppm. Lithium yield $\mathrm{Y}_{\mathrm{Li}}$ exhibits a linear behavior with lithium

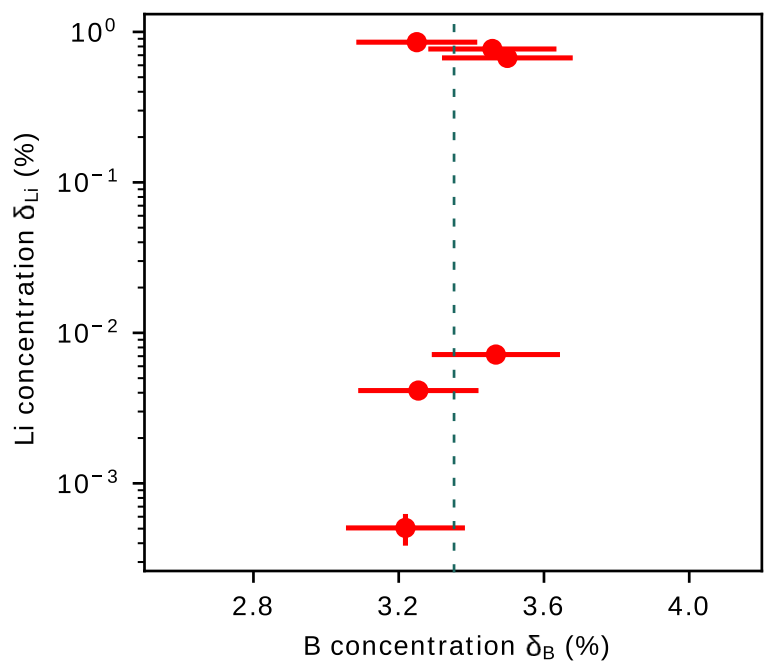

Fig. 6 The lithium content correlation to boron content in the tourmaline samples. The dotted line indicates a boron concentration of $3.27 \%$

concentrations $\delta_{\mathbf{L i}}$ from $40 \mathrm{ppm}$ to $18 \%$. The correlation is given by the linear regression equation: $\delta_{\mathrm{Li}}=11.2(1)$ $[\%] \mathrm{Y}_{\mathrm{Li}}$, which was obtained using data from the Li-minerals. The NIST data fits very well with the linear regression as is shown in Table 1 as well as in an inset of Fig. 5. The continuous and dashed lines are a fit of the data with $\mathrm{R}_{\mathrm{SP}}$ range corrections and a fit without $\mathrm{R}_{\mathrm{SP}}$ range corrections respectively. At low lithium concentration, both fit lines can group the data. However, at high lithium concentration, the fit without $\mathrm{R}_{\mathrm{SP}}$ range corrections does not pass through the last point.

In a second analysis, eight tourmaline crystals were scanned using the same conditions as for the lithium concentration calibration. The boron concentrations in the tourmalines were determined using an equivalence between $\delta_{\mathrm{B}}$ and $\mathrm{Y}_{\mathrm{B}}$. It was acquired using the data from the NISTs and one tourmaline standard sample and this is summarized in Table 2.

To calculate the lithium content, the expression obtained previously, $\delta_{\mathrm{Li}}=11.5(1)[\%] \mathrm{Y}_{\mathrm{Li}}$ was applied to the yields measured in the tourmalines. Figure 6 presents the concentrations of lithium and boron measured in the tourmaline samples. Boron concentration values are about 3.27\%, as expected for tourmalines [15].
Table 2 Boron yield $\mathrm{Y}_{\mathrm{B}}$ and boron concentrations $\delta_{\mathrm{B}}$ for standard reference samples

\begin{tabular}{llll}
\hline Crystal & $\mathrm{Y}_{\mathrm{B}}$ & \multicolumn{2}{l}{$\mathrm{B}$ concentration $\delta_{\mathrm{B}}$} \\
\cline { 3 - 4 } & & $\delta_{\mathrm{B}}=1.98(08) \mathrm{Y}_{\mathrm{B}}$ & Nominal values \\
\hline Tourmaline standard & $1.71(50)$ & $3.40(20) \%$ & $3.27(1) \%$ [27] \\
NIST 610 & $1.66(5) \times 10^{-2}$ & $328(20) \mathrm{ppm}$ & $351 \mathrm{ppm} \mathrm{[24]}$ \\
NIST 612 & $1.74(7) \times 10^{-3}$ & $34(2) \mathrm{ppm}$ & $32 \mathrm{ppm} \mathrm{[25]}$ \\
\hline
\end{tabular}

The concentrations shown in the column Nominal values are taken from the respective references 


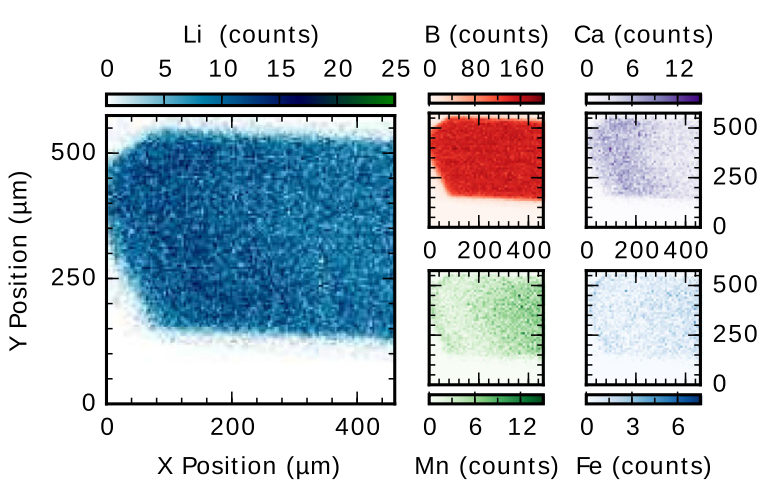

Fig. 7 Lithium, boron, calcium, manganese and iron 2D maps in a tourmaline sample

Regarding the lithium contents in the tourmaline samples, three sets of data present a significant lithium concentration around $0.7 \%$. The remaining sets of data present low lithium contents, ranging from $10 \mathrm{ppm}$ to $100 \mathrm{ppm}$. Tourmalines with lithium content are characteristic of the elbaite tourmaline group; for more details see Ref. [30] sample $61 \mathrm{Vbh}$ and Ref. [31]. According to [32, 33], a very low concentration of $\mathrm{Li}$ in tourmaline is usually assumed to be insignificant, but tourmalines low in Li can present around 10-80 ppm of lithium content [31].

Detection of heavy elements such as calcium and iron were possible to perform using the PIXE technique. As an example, Fig. 7 illustrates 2D map distributions of $\mathrm{Ca}, \mathrm{Mn}$ and $\mathrm{Fe}$ in a tourmaline. Also the $\mathrm{Li}$ and $\mathrm{B}$ distributions are shown in the figure. Clear zonation patterns of $\mathrm{Ca}$ and $\mathrm{Mn}$ are distinguishable in the $2 \mathrm{D}$ maps. A continuous core-torim zoning where $\mathrm{Ca}$ increases as $\mathrm{Mn}$ decreases appears in the 2D maps of $\mathrm{Ca}$ and $\mathrm{Mn}$ presented in Fig. 7. The lithium 2D map also shows a continuous core-to-rim zoning. On the other hand, a homogeneous composition is exhibited in the 2D map of boron.

To investigate the detection limit of lithium, a lithiumfree (below $0.001 \mathrm{ppm}$ ) Suprasil quartz crystal [26] was analyzed using a beam current of $2 \mathrm{nA}$ for $2 \mathrm{~h}$, and no lithium-related signal was found. To determine the sensitivity in this case, where the experiment has not resulted in any events, Poisson statistics for small signals was applied [34]. Thus, for a zero background spectrum, a sensitivity of 4.74 events or counts is given for a confidence level of $99 \%$ $(3 \sigma)$. Assuming a beam current of $4 \mathrm{nA}$ for $1 \mathrm{~h}$, the charge compensated by the live time of the system would be $5 \times 10^{5}$, what leads a lithium yield value of $4.74 / 5 \times 10^{5}$. From the calibration, this lithium yield should correspond to a concentration of $\delta_{\mathrm{Li}}=11.5\left(4.75 / 5 \times 10^{5}\right)[\%]=1 \times$ $10^{-4}[\%],(1 \mathrm{ppm})$.

\section{Summary and conclusions}

Using the reaction ${ }^{7} \mathrm{Li}(\mathrm{p}, \alpha){ }^{4} \mathrm{He}$ with proton energies at $852 \mathrm{keV}$, a fast and background free measurement of isolated $\alpha$-peaks in standard and geological samples was obtained. The analytical technique presented in this work allowed acquiring lithium measurements from 4.3(8) ppm (a tourmaline sample) to 17.7(6) \% (lithiophosphate). Analysis of a Suprasil quartz crystal does not present any signal of lithium, which indicates that for $1 \mathrm{~h}$ analytical time at $4 \mathrm{nA}$, the detection limit of lithium is $1 \mathrm{ppm}$.

The presence and distribution of heavy elements such as iron, calcium and manganese in the lithium minerals or in the tourmaline samples were possible to measure using the PIXE technique simultaneously with the NRA. The results from tourmaline samples exhibit chemical zonations, which have being studied in Ref [16]. The compositional zoning within a specimen shows that an analytical investigation of an arbitrary section of a crystal can introduce possible errors. Hence, the technique performed in this work is a suitable method to track major chemical composition variations in a sample.

\section{Supplementary information}

This section will not appear in the printed version of your paper but it will contain a link; the webpage containing the electronic supplementary information will appear when one clicks on the hyperlink. Here you can list the details of your research which would be too long for the main text, e.g. a larger number of spectra etc. Start with 1 for Figure and Table numbers in this section.

Open Access This article is distributed under the terms of the Creative Commons Attribution 4.0 International License (http://creative commons.org/licenses/by/4.0/), which permits unrestricted use, distribution, and reproduction in any medium, provided you give appropriate credit to the original author(s) and the source, provide a link to the Creative Commons license, and indicate if changes were made.

\section{References}

1. Jackson T (2007) The elements Lithium. Marshall Cavendish Benchmark, New York

2. Greenwood N, Earnshaw A (eds) (1997) Lithium, sodium, potassium, rubidium, caesium and francium. In: Chemistry of the elements. Butterworth-Heinemann, Oxford

3. Talens Peiró L, Villalba Méndez G, Ayres RU (2013) Lithium: sources, production, uses, and recovery outlook. JOM 65:986-996

4. Anders M, Trezzi D, Menegazzo R, Aliotta M, Bellini A, Bemmerer D, Broggini C, Caciolli A, Corvisiero P, Costantini H, Davinson T, Elekes Z, Erhard M, Formicola A, Fülöp Z, Gervino 
G, Guglielmetti A, Gustavino C, Gyürky G, Junker M, Lemut A, Marta M, Mazzocchi C, Prati P, Rossi Alvarez C, Scott DA, Somorjai E, Straniero O, Szücs T (2014) First direct measurement of the ${ }^{2} \mathrm{H}(\alpha, \gamma)^{6} \mathrm{Li}$ cross section at big bang energies and the primordial lithium problem. Phys Rev Lett 113:042501

5. Mota Duarte, de Freitas JLG, Leverson Brian D (2016) Lithium in medicine: mechanisms of action met ions. Life Sci 16:557-584

6. Groot PA (2009) Lithium. In: Groot PA (ed) Handbook of stable isotope analytical techniques. Elsevier, Amsterdam

7. Yamazaki A, Orikasa Y, Chen K, Uchimoto Y, Kamiya T, Koka M, Satoh T, Mima K, Kato Y, Fujita K (2016) In-situ measurement of the lithium distribution in Li-ion batteries using microIBA techniques. Nucl Instrum Methods B 371:298-302

8. Gao Y, Vils F, Cooper KM, Banerjee N, Harris M, Hoefs J, Teagle DAH, Casey JF, Elliott T, Laverne C, Alt JC, Muehlenbachs K (2012) Downhole variation of lithium and oxygen isotopic compositions of oceanic crust at East Pacific Rise. Geochem Geophys Geosyst 13:Q10001

9. Rio S, Métrich N, Mosbah M, Massiot P (1995) Lithium, boron and beryllium in volcanic glasses and minerals studied by nuclear microprobe. Nucl Instrum Methods B 100:141-148

10. Räisänen J (1992) Analysis of lithium by ion beam methods. Nucl Instrum Methods B 66:107-117

11. Nastasi M, Mayer JW, Yongqiang W (eds) (2014) Nuclear reaction analysis. In: Ion beam analysis fundamentals and applications. CRC Press, Boca Raton

12. Wang Y, Natasi M (2009) Handbook of modern ion beam materials analysis, vol 1, 2nd edn. Materials Research Society, Warrendale, Pennsylvania

13. Sullivan R, Pang A, Martinez-Sanchez M, Whyte D (2014) A lithium depth-marker technique for rapid erosion and deposition measurements. Nucl Instrum Methods B 319:79-86

14. De La Rosa N, Kristiansson P, Nilsson EJC, Ros L, Elfman M, Pallon J (2017) Lithium analysis using a double-sided silicon strip detector at LIBAF. Nucl Instrum Methods B 404:29-33

15. Bosi F, Naitza S, Skogby H, Secchi F, Conte AM, Cuccuru S, Hålenius U, De La Rosa N, Kristiansson P, Nilsson EJC, Ros L, Andreozzi GB (2017) Late magmatic controls on the origin of schorlitic and foititic tourmalines from late-Variscan peraluminous granites of the Arbus pluton. Lithos, Submitted

16. Henry DJ, Guidotti CV (1985) Tourmaline as a petrogenetic indicator mineral: an example from the staurolite-grade metapelites of NW Maine. Am Mineral 70:1-15

17. Henry DJ, Novák M, Hawthorne FC, Ertl A, Dutrow B, Uher P, Pezzotta F (2011) Nomenclature of the tourmaline supergroup minerals. Am Mineral 96:895-913

18. Gribble CD, Hall AJ (1992) Optical mineralogy principles and practice. Chapman and Hall, New York

19. Henry DJ, Dutrow BL (1992) Tourmaline in a low grade clastic metasedimentary rock: an example of the petrogenetic potential of tourmaline. Contrib Mineral Petrol 112:203-218
20. Shariff A, Nilsson C, Auzelyte V, Elfman M, Kristiansson P, Malmqvist K, Pallon J, Wegdén M (2005) The Lund nuclear microprobe submicron set-up. Part II: beam line, focusing system and scanning. Nucl Instrum Methods B 231:7-13

21. Elfman M, Pallon J, Auzelyte V, Kristiansson P, Malmqvist K, Nilsson EJC, Shariff A, Wegdén M (2005) The Lund Nuclear Microprobe sub-micron set-up. Part III: sample stage, optical imaging and detector configuration in the experimental chamber. Nucl Instrum Methods B 231:14-20

22. Golubev $\mathrm{P}$, Kristiansson $\mathrm{P}$, Arteaga-Marrero N, Elfman M, Malmqvist K, Nilsson EJC, Nilsson C, Pallon J, Wegdén M (2009) First results from the Lund NMP particle detector system. Nucl Instrum Methods B 267(2065):2068

23. KETEK X-ray Silicon Drift Detector, key parameters. https:// www.ketek.net/sdd/vitus-sdd-modules/vitus-h50/. Accessed 18 Jan 2018

24. National Institute of Standards and Technology Certificate. https://www-s.nist.gov/srmors/certificates/610.pdf. Accessed 18 Jan 2018

25. National Institute of Standards and Technology Certificate. https://www-s.nist.gov/srmors/certificates/612.pdf. Accessed 18 Jan 2018

26. National Institute of Standards and Technology Suprasil crystal. https://www.heraeus.com/media/media/hqs/doc_hqs/products_ and_solutions_8/optics/Data_and_Properties_Optics_fused_ silica_EN.pdf. Accessed 18 Jan 2018

27. Nilsson EJC, Kristiansson P, Ros L, De La Rosa N, Elfman M, Hålenius U, Pallon J, Skogby H (2017) A nuclear geochemical analysis system for boron quantification using a focused ion beam. J Radioanal Nucl Chem 311:355-364

28. Kristiansson P, Borysiuk M, Arteaga-Marrero N, Elfman M, Nilsson EJC, Nilsson C, Pallon J (2010) A pre-sample charge measurement system for quantitative NMP-analysis. Nucl Instrum Methods B 268:1727-1730

29. Ziegler F, Biersack JP, Ziegler MD (2008). SRIM-the stopping and range of ions in matter. SRIM Co. ISBN 0-9654207-1-X. T

30. Bosi F, Andreozzi GB, Federico M, Graziani G, Lucchesi S (2005) Crystal chemistry of the elbaite-schorl series. Am Mineral 90:1784-1792

31. Novák M, Ertl A, Povondra P, Galiová MV, Rossman GR, Pristacz H, Prem M, Giester G, Gadas P, Škoda R (2013) Darrellhenryite, $\mathrm{Na}\left(\mathrm{LiAl}_{2}\right) \mathrm{Al}_{6}\left(\mathrm{BO}_{3}\right)_{3} \mathrm{Si}_{6} \mathrm{O}_{18}(\mathrm{OH})_{3} \mathrm{O}$, a new mineral from the tourmaline supergroup. Am Mineral 98:1886-1892

32. Bosi F, Skogby H, Balić-Žunić T (2016) Thermal stability of extended clusters in dravite: a combined EMP, SREF and FTIR study. Phys Chem Miner 43:395-407

33. Bosi F, Skogby H, Ciriotti ME, Gadas P, Novák M, Cempíek J, Všianský D, Filip J (2016) Lucchesiite $\mathrm{CaFe}_{2}+3 \mathrm{Al}_{6}\left(\mathrm{Si}_{6} \mathrm{O}_{18-}\right.$ )$\left(\mathrm{BO}_{3}\right)_{3}(\mathrm{OH})_{3} \mathrm{O}$, a new mineral species of the tourmaline supergroup. Mineral Mag 81:1-14

34. Feldman GJ, Cousins RD (1998) Unified approach to the classical statistical analysis of small signals. Phys Rev D 57:3873-3889 